\title{
A Orientação Vocacional e Profissional no Ensino Superior em Moçambique: Um Estudo de Caso (Sofala).
}

\author{
Júlio Taimira Chibemo* \& Fernando Canastra** \\ *Instituto Superior de Ciências e Tecnologia Alberto Chipande, **Universidade Católica de Moçambique
}

\begin{abstract}
Resumo
O presente trabalho tem como objectivo central reflectir sobre a necessidade e as implicações da orientação vocacional e profissional, no ensino superior, na Beira (Sofala). A orientação vocacional e profissional (OVP), no contexto do ensino superior, assume uma relevância significativa, considerando, por um lado, as incertezas, a precaridade e a mobilidade permanente no campo da empregabilidade, devido, entre outras razões, à globalização de matriz neoliberal; por outro lado, a competitividade, no mercado de trabalho, gera novas exigências e necessidades, em termos de dinâmicas autoformativas e da necessidade de aprendizagem ao longo da vida. A OVP surge, assim, como uma estratégia-chave necessária, no âmbito do ensino superior, para acompanhar este processo de transição num momento crucial na vida dos estudantes: a sua inserção social e profissional. Contudo, hoje, pede-se algo mais, quando falamos de "transição para a vida activa”, isto é, mais do que acompanhar uma "passagem", trata-se, cada vez mais, de acompanhar e mediar um "percurso" no quadro das trajectórias de vida. É, neste contexto, que se inscreve este estudo, procurando dar conta deste fenómeno, no âmbito das Instituições do Ensino Superior em Sofala. A metodologia adoptada foi o estudo de caso. Na recolha dos dados, usou-se a pesquisa documental, entrevistas semiestruturadas e inquéritos por questionário. Para o tratamento da informação, recorreu-se à técnica de análise de conteúdo e à análise estatística descritiva.
\end{abstract}

Palavras-Chave: Orientação Vocacional e profissional, ensino superior, transição para a vida activa, trajectórias de vida.

\footnotetext{
Abstract

The present work aims to reflect on the central necessity and implications of vocational and professional guidance in higher education, in Beira (Sofala). Vocational and professional orientation (VPO), in the context of higher education assumes a significant relevance, considering, on the one hand, the uncertainties, precariousness and
}

permanent mobility in the field of employability, due, among other reasons, to the globalization neoliberal matrix; on the other hand, the competitiveness in the labour market, generates new demands and requirements, in terms of self-training dynamics and the need for lifelong learning. The VPO arises, therefore, as a key strategy needed, within the framework of higher education, to accompany this transition at a crucial moment in the lives of students: their social and professional insertion. However, today, we need something more, when we speak of "transition to working life", i.e. more than accompany a "passage", that is, increasingly, to monitor and mediate a "route" in the context of the life trajectories. It is in this context that subscribes this study, seeking to give an account of this phenomenon, within the framework of the institutions of higher education in Sofala. The methodology adopted was the case study. In collecting the data, used the documentary research, semi-structured interviews and surveys. For the treatment of information, resorted to the technique of content analysis and descriptive statistical analysis.

Keywords: vocational guidance and vocational training, higher education, transition to working life, life trajectories.

\section{Introdução}

A Orientação Vocacional e Profissional (OVP), no âmbito do ensino superior, tem sido objecto de vários estudos (Ribeiro, 2013). As narrativas produzidas, em torno desta temática, tendem a adoptar vários modelos consoante os quadros de referência, tanto ao nível político, como económico e social. "As mudanças associadas aos processos de globalização, de matriz neoliberal, reclamam, por sua vez, novos discursos ideológicos que procuram impor-se nos diversos contextos de ensino” (Rivizi \& Lingard, 2013).

Este cenário, em que os efeitos do neoliberalismo se fazem sentir, também, no ensino superior, estão a modificar o sentido da OVP. Na realidade, quando, hoje, se pede que a universidade deve, para além da sua missão clássica, que consistia basicamente na transmissão e difusão do conhecimento, preparar, também, os estudantes para a 
vida activa e, mormente, para a sua entrada no mercado de trabalho, mercado esse que se rege, cada vez mais, por uma lógica de competitividade, então a OVP tende a assumir novas configurações, desafiando os modelos tradicionais, que se centravam, predominantemente, em certas fases da trajectória dos indivíduos.

Esta exigência e pressão economicista têm reclamado novas políticas educativas assentes numa base ideológica que privilegia a "produtividade económica", a "liberdade e eficiência do mercado" (Rivizi \& Lingard, 2013, p. 241). Neste sentido, o que se pede à universidade é, acima de tudo, uma estratégia de ensino baseada no desenvolvimento de competências para "aprender a aprender em contexto” e para “se adaptar à mudança constante” ao longo das trajectórias sociais e profissionais dos futuros profissionais (Delors, 1996; Le Boterf, 2003; Perrenoud, 2007; Perrenoud, 2012).

Neste contexto, deve repensar-se a orientação universitária, perspectivando-a, cada vez mais, como uma “orientação”, “acompanhamento” e "mediação”, ao longo das trajectórias de vida dos estudantes e, mais tarde, dos futuros profissionais. Este trabalho de acompanhamento e de mediação tende a impor-se como uma actividade que veio para se desenvolver ao longo da vida, e não apenas em certas fases da vida, como, por exemplo, na chamada "escolha vocacional”, que se fazia na transição do ensino secundário para o ensino superior, e na "inserção profissional” que se fazia entre o ensino superior e o mercado de trabalho. Sem negar estas duas fases importantes na vida dos estudantes, importa perspetivá-las no quadro de outras temporalidades e trajectórias. Pois, como refere Boutinet (2000), na "Imaturidade da Vida Adulta", o processo de aprendizagem, hoje, implica reequacionar as temporalidades da formação e da educação, conferindo-lhes uma nova dinâmica holística. Os indivíduos aprendem a ser “adultos” no quadro das suas trajectórias de vida, particularmente no seio das suas múltiplas e variadas experiências sociais e profissionais.

Assim, ganha, cada vez mais peso, o processo de transição para o ensino superior, nos primeiros anos dos cursos e no próprio processo académico, mesmo antes da entrada para o mercado de trabalho. Daí a importância de desenvolver programas de orientação vocacional, programas de tutoria e acompanhamento pedagógico e programas de transição para a vida activa, investindo numa outra lógica de orientação universitária: "acompanhar o projecto de vida e profissional” dos estudantes e futuros profissionais (Rodriguez Moreno, 2002).

\section{Orientação Vocacional e Profissional: Debate Conceptual}

Orientar é indicar caminhos e rumos, para si alcançar um ponto. A orientação é um "conceito complexo que abarca várias dimensões do saber o que proporciona diversas definições e perspectivas de análise, umas vezes consensuais e outras pouco consensuais” (Tavares, 2009, p.31). Por exemplo, uns enfatizam a componente histórica, outros dão mais importância aos aspectos teórico-conceptual, e, outros ainda, à componente prescritiva, descritiva, normativa ou crítica.

Bisquerra e Alvez (1998, p. 20) referem que a “orientação vocacional e profissional é um processo de constante formulação de propostas de educação, tendo em conta os resultados de intervenções psicopedagógicas, bem como teorias e modelos de intervenção no campo da orientação educativa”.

De acordo com Parsons (1908), considerado pai da orientação voacional e profissional, citado por Rodriguez Moreo (1987, p. 21), refere que "a orientação vocacional e profissional é um processo de formação que exige três actuações principais: análise da pessoa, para conhecer as suas capacidades, interesses e temperamento; a análise das tarefas, para que o orientado conheça os requisitos e as várias oportunidades de trabalho; e, por último, a compreensão conjunta das análises feitas, para permitir uma relação profícua entre o orientado e o orientador”.

Fletcher (1913) define a orientação vocacional e profissional como sendo o "processo de selecção e preparação do estudante para a vida laboral”. Enquanto isso, Claparède (1992, p. 37) pontua que a orientação vocacional e profissional é um “processo de formação que visa dirigir e guiar o estudante para uma profissão que lhe ofereça mais possibilidades e probabilidades de sucesso, correspondendo às suas atitudes psíquicas e físicas”. Em termos práticos, este processo de ensino assenta na tentativa de conhecer o orientando; verificar as aptidões requeridas para uma dada profissão e conhecer o mercado de trabalho disponível.

Nos anos 1940, com a publicação do "Manual de Orientação Profissional” de Mira e López, passouse a dar importância à actuação científica completa e persistente nesse processo com o objectivo de fazer com que cada orientado se dedique a um tipo de trabalho profissional com menor esforço e obtenha rendimentos e satisfação para si e para a sociedade. Portanto, neste contexto, era preciso eleger uma profissão com base em dados que revelasse a atitude e comportamento do orientando, para facilitar seu processo de tomada de decisão (Sinoir, 1954, p. 17 e Gemilli, 1959, p.8). 
Nos anos 1970, surgem as primeiras ideias acerca das funções do orientador graças aos movimentos da Europa e Estados Unidos que passaram a referir que a "orientação" vocacional e profissional implicava um conjunto de tarefas realizadas por orientadores especializados (psicólogos), cujos destinatários eram pessoas que enfrentavam em determinados momentos de suas vidas a possibilidade ou necessidade de decidir sobre sua formação e profissão (Tavares, 2009, p.34).

Desta feita, pode-se chegar à constatação de que a orientação vocacional e profissional é um processo que visa ajudar sistematicamente pessoas em período de formação que necessitam decidir sobre o futuro da sua formação e profissão. Trata-se de proporcionar ao estudante um conjunto de ferramentas para despertar sua vocacão e inclinação para uma área que se identifica com suas habilidades e capacidades, mediante uma intervenção técnica baseada em princípios e intervenções de agentes educativos preparados para tal. Esse processo tem como meta criar a autonomia dos estudantes, no seu percurso académico e profissional. Portanto, a orientação vocacional é a chave do sucesso do estudante que ao longo da sua carreira académica, bem como na sua inserção no mercado de trabalho.

Em termos de relevância deste tipo de formação, a UNESCO, nos finais dos anos 1990, organizou um Congresso Internacional sobre Técnicas Educacionais e Vocacionais, em Seul, onde apelou aos Estados membros da necessidade de promover um "ensino centrado na necessidade de se desenvolver políticas de educação que visem promover habilidades e capacidades dos estudantes, tendo em conta as necessidades de desenvolvimento humano e progressão profissional, onde se procure transmitir conhecimentos, valores, competências e habilidades".

Na perpectiva da UNESCO (2009), há necessidade das instituições de ensino desenvolverem a orientação e aconselhamento dos estudantes cujo objectivo central é habilitar os estudantes para fazer face às novas necessidades e realidades do Novo Milénio e adquirir um equilíbrio entre o ensino, a aprendizagem e o trabalho. Neste contexto, a oferta da formação técnica e vocacional a grupos desfavorecidos e a Estados em desenvolvimento constitui um elemento fundamental para a transformação dessas sociedades (Tang, 2000, citado por Jenschke, 2003, p. 38). Por conseguinte, aqui fica patente a ideia de que a orientação vocacional e profissional é de capital importância para a transformação das sociedades e potencia o estudante com vista aos desafios profissionais com que deverá lidar no decurso das suas trajectórias de vida.

\section{Orientação Académica e Profissional}

A orientação acadêmica é uma relação social levada a cabo pelos docentes, instituições de ensino ou outros actores estatais e não estatais com interesses na área, visando colocar frente a frente o orientador e o orientado, com vista a levar a cabo um conjunto de actividades académicas que vão desde o acompanhamento do estudo, passando por sessões de tutoria, até à organização de programas de transição para a vida activa. Há, neste sentido, uma diferença entre orientação vocacional e profissional e a orientação académica e profissional.

A orientação académica e profissional "é um processo que visa orientar o estudante no seu processo de formação, com vista a responder às exigências da mesma” (IFECTG, 2009, p.3). Trata-se de um processo de orientação com vista a alcançar resultados positivos no processo de ensino e aprendizagem, centrando-se ela centra-se em aspectos como a descrição do curso, corrículo, etapas de formação, docentes, modelos de avaliação. Por conseguinte, para além do acompanhamento vocacional, importa desenvolver dispositivos de acompanhamento social e pedagógico, de modo a facilitar a aquisição de competências para aprender em contexto e ao longo da vida (Le Boterf, 2003; Perrenoud, 2007; 2012).

A orientação universitária tende a ser percebida como uma acção complexa e integradora, onde concorrem várias dimensões: (a) o acompanhamento psico-pedagógico individualizado; (b) a dinamização de sessões tutoriais para trabalho em pequenos grupos; (c) a organização de programas de transição para a vida activa (Rodriguez Moreno, 2002).

Neste contexto, ganha relevância a ideia de que a orientação universitária deve recentrar-se no projecto de vida e profissional dos estudantes e futuros profissionais (Boutinet, 2000; García, 2002; Rodriguez Moreno, 2002). O conceito de "orientação universitária” procura convocar uma abordagem mais integradora e complexa do que se entende, hoje, por orientação vocional e profissional. Na realidade, o desafio que se coloca às universidades é o de promoverem serviços de orientação integrados e que incidam no desenvolvimento de competências para aprender a aprender ao longo da vida (Delors, 1996).

\section{Orientação Universitária: Uma Abordagem Integradora e Holística}

A Orientação Universitária, nos nossos dias, tende a privilegiar uma abordagem integradora e holística, uma vez que o processo de acompanhamento não se restringe a determinados momentos da vida dos estudantes. Para além desta 
orientação pontual (entrada no ensino superior e inserção no mercado de trabalho), o acompanhamento deve incidir na adaptação académica e na concretização do sucesso educativo e, ainda, no desenvolvimento da capacidade de empreender e de se formar numa dinâmica de aprendizagem permanente (Espinar et al., 2010; Gomes, 2003; Marina, 2010).

Esta nova abordagem procura re-interpretar o sentido que, habitualmente, se tem dado ao conceito de “transição para a vida activa”. Para alguns autores (García, 2002; Gomes, 2003), este conceito tem sido interpretado de forma redutora, fixando, apenas, numa fase de transição entre o ensino e o mercado de trabalho. Na realidade, perante cenários de incertezas e precariedade laboral, importa investir na capacidade de adaptação à mudança que se verifica neste mundo globalizado. Deste modo, mais do que acompanhar o processo de transição em si, trata-se de organizar condições que facilitem a mobilização de estratégias de exploração reconstrutiva (Gomes, 2003):

Hoje, em consequência das mudanças imprevisíveis no mundo do trabalho em geral, melhor será perspectivar a intervenção em orientação escolar e profissional como apoio sistemático à gestão da carreira profissional. Esta forma de conceber a intervenção em orientação revela-se mais adequada com a actual dinâmica do mundo do trabalho, na medida em cada vez maior número de trabalhadores vê-se confrontado, ao longo da sua vida activa, com problemas variados e complexos (alterações no modo de desempenho das funções, mudanças de actividade profissional) relacionados com a sua profissão. Isto é, hoje em dia, carreira profissional é, sobretudo, sinónimo de adaptabilidade profissional.

Por conseguinte, o desafio, hoje, da orientação académica e profissional deve procurar reconhecer o papel activo que os estudantes e futuros profissionais desempenham no quadro das suas trajectórias de vida, uma vez que estes terão que aprender em contexto e a adaptar-se, de forma criativa e empreendedora, ao longo de um sinuoso percurso profissional.

O ensino superior deverá "preparar” os estudantes e futuros profissionais para desenvolverem o seu Portefólio de Competências, investindo, particularmente, naquelas que assumem um carácter transversal (entre outras): aprender a aprender, saber trabalhar em equipa, dominar as tecnologias de informação e comunicação, competências sociais e cívicas, espírito de iniciativa e de empreendedorismo, capacidade de adaptabilidade contextual e ecológica (Le Boterf, 2003; Perrenoud, 2007).

A orientação dos estudantes na universidade e o acompanhamento e mediação dos futuros profissionais no contexto social e laboral assumem novas configurações e sentidos, potenciando, por sua vez, novos estilos de vida, atravessados por uma nova sociablidade: a transição tende a constituir-se já não numa "passagem", mas num "percurso", onde cada sujeito é chamado a tornar-se autor das suas trajectórias de vida.

\section{Método}

O estudo que, agora apresentamos, procura dar conta do processo de orientação vocacional e profissional no contexto do ensino superior, em Sofala. Numa primeira aproximação “ao terreno”, constatamos que este campo de intervenção ainda está a dar os primeiros passos. Nesta fase, os resultados que apresentamos revestem-se de um carácter exploratório. Não havendo ainda dados sistemáticos, recolhidos empiricamente, optámos por realizar um estudo de caso.

Considerando que a temática em estudo ainda não reúne dados sistemáticos, no contexto moçambicano, optou-se pela modalidade de Estudo de Casos (Flick, 2005). Esta metodologia permite um acesso aos contextos naturais para perceber, in loco, a complexidade de um fenómeno.

No nosso caso, a opção por um estudo de caso, na Província de Sofala, justifica-se pelo facto de termos várias instituições do ensino superior. Com esta opção metodológica quisemos aprofundar esta temática, considerando a escassez de dados empíricos. Assim, numa primeira fase deste estudo, decidimos entrevistar os responsáveis das instituições do ensino superior, neste contexto geográfico, de modo a percebermos o que efectivamente se está a fazer neste campo relacionado com a orientação vocacional e profissional.

\section{Participantes}

Participaram, neste estudo exploratório, as seguintes instituições: Universidade Pedagógica, Universidade Católica, Universidade Zambeze, Universidade Jean Piaget e o Instituto Superior de Ciências e Tecnologia Alberto Chipande. Numa primeira aproximação, optámos por inquirir os responsáveis das instituições ou seus representantes, pelo facto de estarmos a dar início ao estudo que, numa fase posterior, irá inquirir, também, outros actores (como, por exemplo, os docentes e estudantes).

\section{Instrumentos e procedimentos}

A principal técnica usada, para recolha dos dados empíricos, foi a entrevista semi-estruturada (Flick, 2005). Este tipo de entrevista permite que se use um guião com algumas questões formuladas previamente, ainda que, no momento da sua 
realização, haja espaço para acomodar as mesmas ao ritmo dos entrevistados. Pretende-se, ainda, nesta fase, explorar e aprofundar o papel da orientação vocacional e profissional no contexto das instituições do ensino superior, na Província de Sofala. Posteriormente, com base na análise dos resultados exploratórios (a partir das entrevistas), aplicámos um Inquérito por Questionário dirigido aos estudantes das diversas instituições, que são objecto deste estudo. Por sua vez, ao nível dos docentes, de no sentido de problematizar este campo de intervenção, recorremos à técnica de Discussão de Grupos (Flick, 2005; Sampieri, Collado \& Lucio, 2006).

\section{Apresentação e Discussão dos Resultados}

O ensino superior integra um ciclo educativo em que a educação oferecida pelas universidades, escolas e institutos superiores, sem prejuízo do estabelecido na Lei $n^{\circ}$. 27/2009, de 29 de Setembro, Lei do Ensino Superior. Tendo em conta os desafios da orientação vocacional e profissional no ensino superior moçambicano, há que procurar entender os significados que se atribuem à Orientação Vocacional e Profissional por parte das instituições de ensino superior da Cidade da Beira; perceber se existe uma estratégia definida sobre para a mesma; identificar as iniciativas e actividades levadas a cabo neste âmbito, as estatísticas sobre a empregabilidade dos cursos e os principais desafios que a instituição tem pela frente no campo.

Uma das questões cruciais no processo de orientações vocacional e profissional no ensino superior tem que ver com o apoio que os estudantes do $1^{\circ}$ ano devem ter no seu processo de adaptação ao ensino superior, uma vez que esse ciclo de formação possui exigências específicas. No universo das instituições do ensino superior que funcionam na Cidade da Beira, o grande apoio que elas têm prestado, especificamente, para estes estudantes é a disponibilização de informação e o esclarecimento das preocupações que estes apresentam. Um dos aspectos interessantes são os esforços por elas elevadas a cabo para criar um ambiente que possibilite a aproximação da associação de estudante às direcções, de modo a tornar o estudante membro e actor da resolução dos desafios envolventes na sua formação.

A orientação vocacional e profissional do estudante deve ter em conta uma formação de cidadãos competentes e empreendedores. Desta feita, o envolvimento do sector público e privado para o sucesso da educação profissional é fundamental, porque no mundo contemporâneo, a educação vocacional e profissional desafia as instituições de ensino a criarem um novo modelo de escola "voltadas não apenas para dentro dos quatro muros, currículos rígidos, professores fechados no interior das salas de aula, horários escolares desajustados, organização tradicional das turmas e dos ciclos de ensino" (Pereira e Vieira, 2006, p. 113). A educação vocacional e profissional é muito mais do que o edifício e os programas ministrados no processo de ensino e aprendizagem.

A pesquisa empírica foi realizada nas instituições de ensino superior da Cidade da Beira, Província de Sofala, em Moçambique, das quais quatro são universidades e uma é instituto superior, nomeadamente, a Universidade Pedagógica, UNIZAMBEZE, Universidade Católica, UNIPIAGET e ISCTAC. Os dados recolhidos ao longo do estudo foram sistematizados com ajuda do programa informático conhecido por "CSPro", enquanto o processamento e tabulação foi efectuado através do programa estatístico "SPSS for Windows". Desta feita, o estudo apresenta indicadores quantitativos e qualitativos, através de tabelas e gráficos. Esses dados procuram reproduzir as percepções e acções dos inqueridos nas instituições de ensino superior que operam na Cidade da Beira. Portanto, a leitura e cruzamento dos dados foram feitos tendo em conta a percentagem dos indicadores.

Nas cinco instituições de ensino superior onde o estudo foi levado a cabo, o universo dos inqueridos foi de 1167 casos. Deste universo, 50\% eram do sexo masculino, contra $49.5 \%$ que foram do sexo feminino e $0.5 \%$ não responderam a pergunta. Desse universo de inqueridos, a maioria (72.2\%) tem a idade compreendida entre 18 a 25 anos de idade, contra $0.3 \%$ que tem acima de 50 anos e outros $0.3 \%$ que não deu qualquer resposta em relação a sua idade; $16.0 \%$ têm entre 26 a 35 anos, contra $4.9 \%$ que tem a idade compreendida entre 15 a 17 anos, enquanto $6.2 \%$ que tem a idade compreendida entre 36 a 50 anos.

A tabela, abaixo, apresenta a amostra da pesquisa tendo em conta a sua distribuição com base nas instituições de formação dos inqueridos.

\begin{tabular}{|lrr|}
\hline $\begin{array}{c}\text { Tabela 1: Distribuição da Amostra Por Instituição } \\
\text { de Formação do Inquerido } \\
\text { Instituições de }\end{array}$ & $\begin{array}{c}\text { Casos } \\
\text { Ensino Superior }\end{array}$ & Percentagem \\
\hline UP & 215 & $18.4 \%$ \\
UNIZAMBEZE & 350 & $30.0 \%$ \\
Universidade Católica & 366 & $31.4 \%$ \\
UNIPIAGET & 57 & $4.9 \%$ \\
ISCTAC & 179 & $15.3 \%$ \\
Total & $\mathbf{1 1 6 7}$ & $\mathbf{1 0 0 \%}$ \\
\hline
\end{tabular}

De acordo com os dados patentes na tabela, acima, pode-se constatar que a maioria dos 
inqueridos frequenta a Universidade Católica (31.4\%) e a UNIZAMBEZE (30.0\%), contra apenas $4.9 \%$ que frequenta a UNIPIAGET, $15.5 \%$ o ISCTAC e $18.4 \%$ a Universidade Pedagógica. A maioria dos inqueridos frequentam cursos da área das ciências, como demonstra o gráfico, abaixo.

Gráfico 1: Área de Estudo em que se Encontram a Frequentar

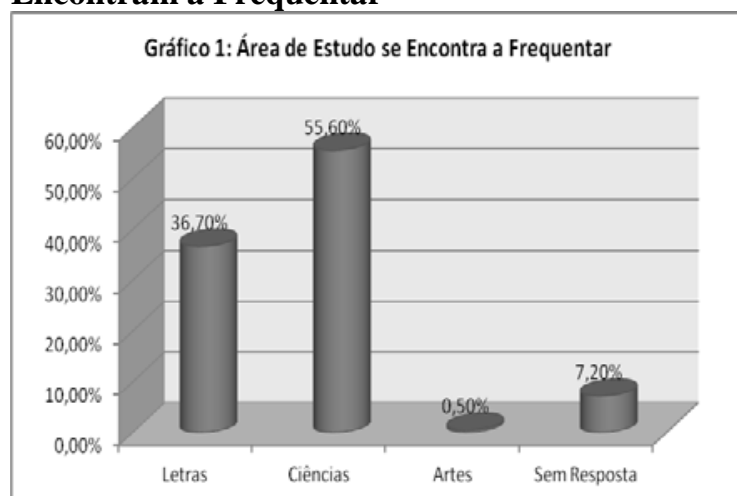

De acordo com os dados patentes no gráfico, acima, pode-se constatar que maioria dos inqueridos que participaram do estudo frequentam cursos da área das ciências (55.6\%), conta apenas $0.5 \%$ que frequentam cursos relacionados com belas artes, enquanto $36.7 \%$ frequentam cursos de letras e $7.2 \%$ não deram qualquer resposta a questão. Por seu turno, quando questionados sobre a área de estudo que mais gostava no ensino pré-universitário, a maioria dos inqueridos apontou para a área das ciências (52.4\%), contra apenas $0.6 \%$ que apontou para as belas artes, enquanto $40.0 \%$ apontou para área das letras e $7.0 \%$ não deu qualquer resposta.

Quando questionados se estavam a frequentar o curso sempre desejado, $73.4 \%$ dos inqueridos respondeu positivamente, contra $26.4 \%$ que respondeu negativamente, enquanto $0.5 \%$ não deu qualquer resposta. A tabela, abaixo, apresenta as respostas dos inqueridos quando questionados quais são as principais razões para estar ou não a frequentar o curso que sempre desejou.

\begin{tabular}{lrr}
\hline \multicolumn{2}{c}{ Tabela 2: Se não, quais são as principais razões } \\
$\begin{array}{l}\text { Opções dos Para } \\
\text { Cursos }\end{array}$ & \multicolumn{1}{c}{ Casos } & $\begin{array}{r}\text { Percentagem } \\
\text { Primeira Opção }\end{array}$ \\
Segunda Opção & 852 & $73.0 \%$ \\
Frequenta Por & 177 & $15.2 \%$ \\
Obrigação & 49 & $4.2 \%$ \\
Dificuldade & & \\
Financeira & 51 & $4.4 \%$ \\
Sem Resposta & & \\
Total & 38 & $3.3 \%$ \\
\hline
\end{tabular}

Dos inqueridos que afirmaram que estão a frequentar o curso sempre desejado, apontaram como principais razões o facto de o curso ser a sua primeira opção (73.0\%), contra $4.4 \%$ que apontaram que encontram-se a frequentar o curso por dificuldades financeiras, uma vez que não possuem condições para custear o curso desejado. Por seu turno, 15.2\% apontaram que o curso que estão a frequentar é a sua segunda opção, contra $4.2 \%$ que frequentam o curso porque foram obrigados pela instituição em que se encontra a trabalhar, familiares ou a entidade que custeia os custos da sua formação. Do universo que respondeu a esta pergunta, 3.3\% não deu qualquer resposta.

\begin{tabular}{|c|c|c|}
\hline \multicolumn{3}{|c|}{$\begin{array}{c}\text { Tabela 3: Razões/Critérios da Escolha do Curso } \\
\text { que Frequenta }\end{array}$} \\
\hline Principais Razões & Casos & Percentagem \\
\hline Pessoais & 485 & $41.6 \%$ \\
\hline Familiares & 85 & $7.3 \%$ \\
\hline Sociais/Económicas & 110 & $9.4 \%$ \\
\hline Vocacionais & 179 & $15.3 \%$ \\
\hline Profissionais & 244 & $20.9 \%$ \\
\hline Obrigações & 19 & $1.6 \%$ \\
\hline Sem resposta & 27 & $2.3 \%$ \\
\hline Vocacionais, & 2 & $0.2 \%$ \\
\hline Profissionais & & \\
\hline Pessoais, familiares & 16 & $1.4 \%$ \\
\hline Total & 1167 & $100 \%$ \\
\hline
\end{tabular}

Para a maioria dos inqueridos (41.6\%) tem razões pessoais entre as principais razões e critérios da escolha do curso que frequenta, contra $0.2 \%$ que tem razões e critérios vocacionais e profissionais, de forma conjugada. Enquanto isso, de forma separada, $20.9 \%$ tem razões e critérios profissionais, contra $15.3 \%$ que tem critérios e vocacionais, contra 1.6\% que são obrigados e $1.4 \%$ que tem critérios e razões familiares.

\begin{tabular}{|c|c|c|}
\hline \multicolumn{3}{|c|}{$\begin{array}{l}\text { Tabela 4: Quem o ajudou na escolha do curso que } \\
\text { se encontra a frequentar }\end{array}$} \\
\hline Entidades & Casos & Percentagem \\
\hline Familiares & 611 & $52.4 \%$ \\
\hline Familiares e Professor & 6 & $0.5 \%$ \\
\hline Professor & 61 & $5.2 \%$ \\
\hline Palestras & 96 & $8.2 \%$ \\
\hline Gabinetes & 37 & $3.2 \%$ \\
\hline Orientações Feitas nas & 82 & $7.0 \%$ \\
\hline $\begin{array}{l}\text { Escolas ou Equipe de } \\
\text { Universidades }\end{array}$ & & \\
\hline Sem ajuda & 179 & $15.3 \%$ \\
\hline Amigos & 30 & $2.6 \%$ \\
\hline Publicidade & 6 & $0.5 \%$ \\
\hline Sem Resposta & 59 & $5.1 \%$ \\
\hline Total & 1167 & $100 \%$ \\
\hline
\end{tabular}


Para a maioria dos inqueridos os familiares (52.4\%) são quem os ajudou na escolha do curso que se encontra a frequentar, contra $0.5 \%$ que escolheram o curso devido a publicidades. Para 15.3\% escolheram o curso que frequenta sem ajuda alguma, enquanto $8.2 \%$ tiveram informações sobre os cursos em palestras, $7.0 \%$ graças às orientações legadas a cabo nas escolas ou equipe de universidades e $5.2 \%$ foram influenciados pelos professores. Os gabinetes de orientação vocacional e profissional tem muito pouca influência, com apenas $3.2 \%$ dos inqueridos a apontar esta entidade como sendo aquela que os ajudou a escolher o curso. Importa referir que nas instituições de ensino superior em Sofala quase que não existem gabinetes de apoio vocacional e profissional.

O gráfico, abaixo, apresenta as percepções dos inqueridos das quatro instituições de ensino superior que operam na Cidade da Beira sobre o tipo de apoio que teve na instituição onde frequentou o ensino pré - universitário.

\section{Gráfico 2: Tipo de Apoio Que Teve na Instituição Onde Frequentou o Ensino Pré- Universitário}

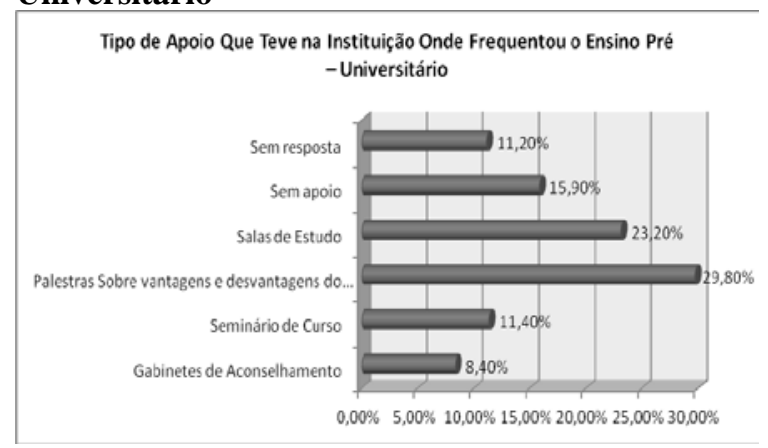

De acordo com os dados patentes no gráfico, acima, pode-se notar que quando questionados sobre o tipo de apoio que teve na instituição onde frequentou o ensino pré - universitário, 29.8\% apontou que teve apoio para decidir por um curso em palestras sobre vantagens e desvantagens do curso, contra $11.2 \%$ que teve o referido apoio em seminários ao longo do curso. As aulas em sala de aulas foi um apoio determinante para a escolha do curso para $23.2 \%$, contra $15.9 \%$ qua não teve apoio para decidir que curso frequentar, enquanto apenas 8.4\% teve apoio para decidir que curso seguir junto dos gabinetes de aconselhamento. Importa referir que $11.2 \%$ dos inqueridos não deu qualquer resposta a pergunta.

Tabela 5: Mecanismos de Apoio a Inserção no Mercado de Trabalho a Instituição Proporciona Mecanismos de Apoio Casos Percentagem

\begin{tabular}{lrr} 
Palestras & 300 & $25.7 \%$ \\
Simulações Empresariais & 90 & $7.7 \%$ \\
Seminários & 98 & $8.4 \%$ \\
Visitas de Estudo & 92 & $7.9 \%$ \\
Estágios Profissionais & 502 & $43.0 \%$ \\
Palestras, Simulações & 12 & $1.0 \%$ \\
Empresariais, Estágios & & \\
Profissionais & & \\
Sem Resposta & 73 & $6.3 \%$ \\
Total & $\mathbf{1 1 6 7}$ & $\mathbf{1 0 0 \%}$ \\
\hline
\end{tabular}

Os dados patentes na tabela acima, demonstram que quando questionados sobre os mecanismos de apoio a inserção no mercado de trabalho a instituição proporciona, 43\% dos inqueridos apontou para estágios profissionais, contra $1.0 \%$ que apontou para palestras, simulações empresariais, estágios profissionais, enquanto $25.7 \%$ que apontou para palestras, contra $7.7 \%$ que apontou para simulações empresariais e $7.9 \%$ que apontou para visitas de estudo e $8.4 \%$ que apontou para seminários.

De acordo com os inqueridos, $77.5 \%$ não teve dificuldades na escolha do curso de ensino superior, contra $19.7 \%$ que respondeu que teve dificuldades e $2.7 \%$ não deu qualquer resposta. Dos que apontaram que tiveram dificuldades, $4.5 \%$ apontou que houve imposição na escolha do curso, contra $0.3 \%$ que apontou para 0 facto de ter dificuldades de acompanhamento da língua inglesa e $2.4 \%$ olhava para o nível de empregabilidade do curso, depois da sua formação.

O gráfico, abaixo, apresenta as percepções dos inqueridos sobre a necessidade de melhoramento do processo de integração no ensino superior.

Gráfico 3: Melhoramento do Processo de Integração no Ensino Superior

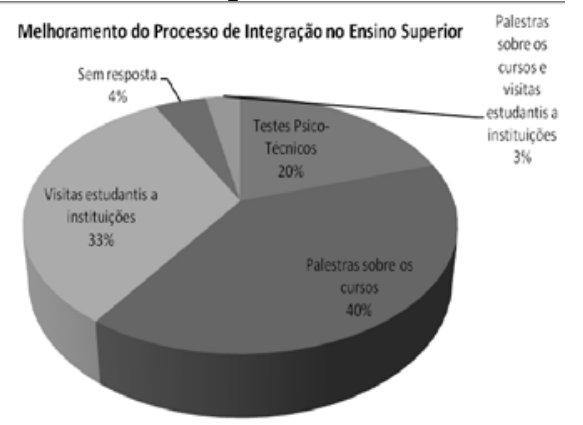

Diante dos desafios, incertezas e dificuldades para decidir por um curso a frequentar no ensino superior, $39.6 \%$ dos inqueridos referiram que as instituições de ensino superior deviam intervir mais em áreas como realização de palestras sobre os cursos, contra $3.1 \%$ que apontou para a necessidade 
de serem realizadas mais palestras sobre os cursos e visitas estudantis a instituições. Por seu turno, 32.6\% dos inqueridos apontou para a necessidades de serem levadas a cabo mais visitas estudantis a instituições, contra $20.1 \%$ que apontaram para a necessidade de realizar testes psico-técnicos para verificar a personalidade dos estudantes, suas capacidades e habilidades, bem como as suas inclinações vocacionais e profissionais.

\begin{tabular}{|c|c|c|}
\hline \multicolumn{3}{|c|}{$\begin{array}{l}\text { Tabela 6: Mudança no processo de acolhimento } \\
\text { dos estudantes do } 1^{\circ} \text { ano }\end{array}$} \\
\hline Mudanças & Casos & Percentagem \\
\hline $\begin{array}{l}\text { Mais Dialogo, } \\
\text { Conselho e } \\
\text { Motivação }\end{array}$ & 358 & $30.7 \%$ \\
\hline Mais Palestras & 121 & $10.4 \%$ \\
\hline Início Tardio & 4 & $0.3 \%$ \\
\hline Nada & 332 & $28.4 \%$ \\
\hline Sem Resposta & 341 & $29.2 \%$ \\
\hline Alojamento & 11 & $0.9 \%$ \\
\hline Total & 1167 & $100 \%$ \\
\hline
\end{tabular}

Os dados patentes na tabela, acima, demonstram que as respostas dadas pelos inqueridos são dispersas. Todavia, para os estudantes do primeiro ano, há necessidade de serem realizadas mudanças no processo do seu acolhimento quando ingressam no ensino superior. Do universo dos inqueridos, 30.75 apontou que há que se criar mais condições de diálogo, conselho e motivação dos estudantes, contra apenas $0.9 \%$ que apontou para a disponibilização de alojamento, enquanto $10.4 \%$ apontou para a necessidade de se criar mais oportunidades de palestras, contra $28.4 \%$ que apontou que não há necessidade de se realizar qualquer mudança.

\section{Considerações Finais}

A orientação vocacional e profissional nas instituições de ensino superior é uma relação social e académica que envolve estudantes, docentes, instituições de ensino ou outros actores estatais e não estatais, com interesses na melhoria da qualidade de formação dos estudantes envolvidos num processo formativo e a sua integração futura no mercado de trabalho bem como a realização numa carreira profissional. Portanto, trata-se de cum conjunto de intenções, acções e actividades que envolvem acompanhamento do estudo, tutoria, até à organização de programas de transição para a vida laboral activa.

Depois de problematizar e discutir os contornos da Orientação Vocacional e Profissional no Ensino Superior, tendo em conta a realidade das instituições de ensino superior, que existem na Cidade da Beira, chega-se à conclusão que, embora pratiquem uma orientação académica e profissional, a componente de orientação vocacional é quase inexistente. Pelos dados recolhidos percebe-se que os estudantes, particularmente quando entram para o ensino superior, não são acompanhados no seu processo vocacional e profissional, particularmente pela fala de investimentos em estruturas de apoio psico-social e psico-pedagógico. Por outro lado, verifica-se que não existe, em nenhuma das instituições inqueridas, um Gabinete de Apoio psicológico-pedagógico, de modo a acompanhar o discernimento vocacional e profissional.

Embora algumas delas tenham, no currículo, disciplinas de "orientação universitária”, acaba por ser, apenas, mais um momento onde os estudantes "recebem uma informação" sobre os processos de orientação académica. Todavia, o papel da orientação vocacional e profissional, enquanto estratégia de facilitação de desenvolvimento de competências interpessoais e profissionais, ainda continua a ser desvalorizado pelas instituições inqueridas. Por conseguinte, nota-se que o principal desafio que se coloca, na vertente da orientação vocacional e profissional, nestas instituições do ensino superior, prende-se com a necessidade de se criarem estruturas de apoio, na vertente psicológica e vocacional, que possam acompanhar os processos biográficos e profissionais dos estudantes e futuros profissionais.

\section{Referências bibliográficas}

Bisqueira, A. \& Gonzalez, A. (1996). Modelos de Intervención em Orientación. Barcelona: Pracxis

Boutinet, J. (2000). Imaturidade da Vida Adulta. Porto: Rés-Editora.

Claparèdes, E. (1992). Orientação Vocacional: Seus Problemas e Métodos. Madrid: Edições dela Lectura.

Flick, U. (2005). Métodos qualitativos na investigação científica. Lisboa: Monitor.

Gemilli, A. (1959). Orientação Profissional. Madrid: Editorial Razón.

Gomes, C. (2003). Novo modelo de intervenção em contexto de transição para a vida activa. http://www.psicologia.pt/artigos/imprimir.ph $\mathrm{p}$ ?Codigo $=\mathrm{A} 0140$

Instituto Federal de Educação, Ciências e Tecnologias (2009). Cartilha de Orientação Acadêmica. Goiânia. Campus Uruaça.

Jenschke, B. (2003). Cooperação Internacional: Desafios e Necessidades da Orientação e do Aconselhamento em Face das Mudanças Mundiais no Trabalho e na Sociedade. IV Simpósio de Orientação Profissional e 


\section{CHIBEMO \& CANASTRA}

Vocacional. Valinhos, 11-13 de Outubro de 2001. Revista Brasileira de Orientação Profissional. $N^{\circ} 04,1 / 2$. pp. 35-55.

Le Boterf, G. (2003). Desenvolvendo a competência dos profissionais (3. Ed.). Porto Alegre: Artmed.

Lei $n^{\circ}$. 27/2009, de 29 de Setembro, Lei do Ensino Superior, Imprensa Nacional, Maputo.

Oliveira, P. (1998). Introdução à Sociologia da Educação. São Paulo: Editora Ática.

Pereira, H. \& Vieira, M. (2006). Entrevista: Pela Educação, com António Noa. Revista Saber e Educar, $N^{\circ} 11$, pp. 111-126.

Perrenoud, Ph. (2007). Diez nuevas competencias para enseñar: invitación al viaje ( $5^{\mathrm{a}}$ ed.). Barcelona: Graó.

Perrenoud, Ph. (2012). Cuando la escuela pretende preparar para la vida. Desarrollar competencias o enseñar otros saberes? Barcelona: Graó.

Rizivi, F. \& Lingard, B. (2013). Políticas educativas en un mundo globalizado. Madrid: Morata.

Sampieri, H., Collado, C. \& Lucio, P. (2006). Metodologia de pesquisa ( $3^{\mathrm{a}}$ ed.). São Paulo: McGraw -Hill.

Tang, Q. (2000). New Challenges to Technical and Vocational Education Plenary session presented at the International Conference for Vocational Guidance. September. Berlin.

Tavares, V. (2009). Orientação Vocacional $e$ Profissional: Um Estido Sobre o Funcionamento das Estruturas de Orientação nas Escolas do Ditrito de Braga. Granada: Editorial de la Universidade de Granada.

UNESCO (1999). Congresso Internacional de Técnicas Educacionais e Vocacionais, Seul. 